Surgery for

Congenital

Heart Disease

\title{
Insulin-like growth factor 1 improves the relationship between systemic oxygen consumption and delivery in piglets after cardiopulmonary bypass
}

Jia Li, MD, PhD ${ }^{a}$

Elisabeth Stenbøg, MD, $\mathrm{PhD}^{\mathrm{b}, \mathrm{c}}$

Andrew Bush, MD, FRCPd

Thorbjørn Grøfte, MD, $\mathrm{PhD}^{\mathrm{c}}$

Andrew N. Redington, MD, FRCPa

Daniel J. Penny, MD, FRCPI ${ }^{\mathrm{e}}$
From the Division of Cardiology, Hospital for Sick Children, Toronto, Ontario, Canada, ${ }^{\mathrm{a}}$ the Department of Paediatrics ${ }^{\mathrm{b}}$ and The Institute of Experimental Clinical Research, ${ }^{\mathrm{c}}$ Aarhus University Hospital, Aarhus, Denmark, the Department of Paediatric Respiratory Medicine, Royal Brompton Hospital, London, United Kingdom, ${ }^{\mathrm{d}}$ and the Department of Cardiology, Royal Children's Hospital, Melbourne, Australia. $^{\mathrm{e}}$

Supported by the British Heart Foundation. Received for publication May 23, 2003; revisions requested July 26, 2003; revisions received Aug 11, 2003; accepted for publication Sept 18, 2003.

Address for reprints: Daniel J. Penny, MD, FRCPI, Department of Cardiology, Royal Children's Hospital, Parkville, Melbourne, Australia 3052 (E-mail: dan.penny@rch. org.au).

J Thorac Cardiovasc Surg 2004;127:1436-41 $0022-5223 / \$ 30.00$

Copyright ( $\odot 2004$ by The American Association for Thoracic Surgery

doi:10.1016/j.jtcvs.2003.08.044
Objective: We sought to assess the effects of insulin-like growth factor 1 on the balance between systemic oxygen consumption and oxygen delivery after cardiopulmonary bypass in piglets.

Methods: Twelve piglets weighing 4.5 to $8.3 \mathrm{~kg}$ undergoing hypothermic $\left(28^{\circ} \mathrm{C}\right)$ cardiopulmonary bypass for 70 to 120 minutes with 40 minutes of aortic crossclamping were studied before and during the first 6 hours after cardiopulmonary bypass. Oxygen consumption was continuously measured by an indirect calorimeter, Deltatrac II MBM-200 Metabolic Monitor (Datex Division Instrumentarium, Helsinki, Finland). Oxygen delivery and cardiac output were calculated from oxygen consumption and the arterial and mixed venous oxygen contents sampled before and every 30 minutes after cardiopulmonary bypass. Oxygen extraction ratio was derived by the ratio of oxygen consumption to oxygen delivery. Arterial blood lactate was measured before and every 30 minutes after cardiopulmonary bypass. Six animals were randomly assigned to receive an intravenous infusion of insulinlike growth factor 1 at $1.2 \mathrm{mg} / \mathrm{h}$ from 1 to 6 hours after cardiopulmonary bypass; the remaining 6 served as a control group.

Results: Relative to the control group, intravenous infusion of insulin-like growth factor 1 significantly reduced oxygen consumption $(P=.02)$ and increased cardiac output $(P=.016)$ and oxygen delivery $(P=.049)$ during the first 6 hours after surgery with hypothermic cardiopulmonary bypass. As a result, oxygen extraction was significantly decreased $(P=.012)$.

Conclusions: Intravenous infusion of insulin-like growth factor 1 improved oxygen transport by reducing oxygen consumption as well as increasing cardiac output and oxygen delivery during the first 6 hours after cardiopulmonary bypass in piglets. This may have important clinical implications for the care of critically ill children after surgery with cardiopulmonary bypass.

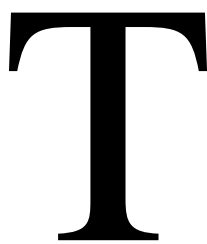

he balance between systemic oxygen delivery $\left(\mathrm{Do}_{2}\right)$ and oxygen consumption $\left(\mathrm{V}_{\mathrm{O}_{2}}\right)$ is impaired after surgery with cardiopulmonary bypass (CPB). $\mathrm{Do}_{2}$ is typically decreased as a result of diminished cardiac output (CO), whereas $\dot{\mathrm{VO}}_{2}$ may be increased, reflecting a hypercatabolic response. The hypercatabolism has been shown to be in part a consequence of a disordered growth hormone and insulinlike growth factor (IGF-1) axis, with depressed IGF-1 levels having been reported 
in patients after $\mathrm{CPB}^{1}$ and other critical illness. ${ }^{2-5}$ Recently, there has been considerable interest in the role of IGF-1 in illness-related hypercatabolism. First, circulating IGF-1 has been confirmed to have a tonic role in sustaining a general anabolic state and therefore potentially could reduce $\dot{\mathrm{V}}_{2}$ by countering the catabolic response. ${ }^{6-9}$ Second, IGF-1 has been shown to have positive inotropic properties by sensitizing the myofilaments to calcium ion, ${ }^{10}$ which may increase $\mathrm{CO}$ and $\mathrm{Do}_{2}$.

Nonetheless, there have been no data reported on the effect of IGF-1 on the overall balance of oxygen transport. The aim of our study was therefore to assess the effects of IGF-1 on the balance between $\dot{\mathrm{V}}_{2}$ and $\mathrm{Do}_{2}$ after $\mathrm{CPB}$ in young animals.

\section{Methods}

\section{Anesthesia}

The institutional animal research committee approved the use of Danish Landrace pigs. Twelve animals, aged 2 to 3 weeks and weighing 4.5 to $8.3 \mathrm{~kg}$ (mean $6.7 \mathrm{~kg}$ ), were medicated intramuscularly with ketamine $(100 \mathrm{mg})$ and midazolam $(5 \mathrm{mg})$. All were intubated with cuffed endotracheal tubes and mechanically ventilated with volume-cycled, intermittent, positive-pressure ventilation (Servo 900C; Siemens Medical Systems, Solna, Sweden). Anesthesia was subsequently maintained with a continuous intravenous infusion of fentanyl $(300 \mu \mathrm{g} / \mathrm{h})$, midazolam $(20 \mathrm{mg} / \mathrm{h})$, and pancuronium bromide $(2 \mathrm{mg} / \mathrm{h})$. The right carotid artery and internal jugular vein were cannulated for arterial pressure monitoring, blood sampling, and infusions. Bladder catheterization was performed.

\section{CPB}

After median sternotomy and heparinization (unfractionated heparin at $300 \mathrm{IU} / \mathrm{kg}$ ), a pulmonary arterial line was inserted. Animals underwent $\mathrm{CPB}$ with a standard clinical neonatal circuit with cannulation of the ascending aorta and right atrium (Stöckert 2.6F and right-angled 20F cannula; Medtronic DLP, Grand Rapids, Mich), a hollow-fiber membrane oxygenator (Dideco SpA, Mirandola, Italy), and a twin roller pump (JOSTRA Medizintechnik AG, Hirrlingen, Germany). The bypass machine was primed with 350 $\mathrm{mL}$ whole blood. Animals underwent 70 to 120 minutes (mean 87 minutes) of hypothermic CPB $\left(28^{\circ} \mathrm{C}\right)$ with 40 minutes of aortic crossclamping and cardioplegic arrest $\left(4^{\circ} \mathrm{C}\right.$, St Thomas solution, $30 \mathrm{~mL} / \mathrm{kg}$ ). CPB was continued during rewarming, until rectal temperature was restored to $38^{\circ} \mathrm{C}$ and hemodynamic stability was achieved. Throughout CPB, the nonpulsatile flow was maintained between 75 and $100 \mathrm{~mL} / \mathrm{kg}$ so that the mean perfusion pressure was adjusted between 40 and $50 \mathrm{~mm} \mathrm{Hg}$, with additional use of nitroglycerin for vasodilation as required. Protamine sulfate $(1 \mathrm{~mL} / 1000 \mathrm{IU}$ heparin) was given immediately after CPB. Positive-pressure ventilation was recommenced after discontinuation of CPB.

\section{Post-CPB Care}

Routine intensive care vital signs (blood pressure, heart rate, central venous pressure, pulmonary arterial pressure, rectal temperature, and urinary output) and ventilator tidal volumes and pressures were continuously monitored. An electric warming blanket was used; otherwise, no adjustments were made to temperature during the experiments. Hemoglobin was maintained at 5 to $7 \mathrm{~g} / \mathrm{dL}$ with donor blood, and hematocrit was kept at around $20 \%$. Throughout the experiments, a fluid containing $20-\mathrm{mmol} / \mathrm{L}$ potassium chloride, 20.5-mmol/L sodium chloride, and 2.31-mmol/L glucose was infused through a central venous line. Dobutamine and nitroglycerin were used according to hemodynamic conditions. The aim was to maintain a systolic arterial blood pressure of more than 70 to $80 \mathrm{~mm} \mathrm{Hg}$, a urinary output of more than $1 \mathrm{~mL} /(\mathrm{kg}$ - h), adequate peripheral perfusion, and a nonacidotic state. Additional $20 \%$ glucose was infused in the IGF-1 group, with the rate adjusted to maintain the glucose levels above $4 \mathrm{mmol} / \mathrm{L}$.

\section{Methods of Measurement}

$\dot{\boldsymbol{V}} \boldsymbol{o}_{2}$. $\dot{\mathrm{V}}_{2}$ was measured continuously by respiratory gas analysis with an open-circuit indirect calorimeter, Deltatrac II MBM200 Metabolic Monitor (Datex Division Instrumentarium, Helsinki, Finland). ${ }^{11,12}$ This calorimeter contains a fast differential paramagnetic oxygen sensor to measure a difference between inspired and expired concentrations and the absolute concentration in the inspired gas, an infrared carbon dioxide sensor, and a gas dilution system to measure flow. The apparatus has been described in detail previously elsewhere. ${ }^{13,14}$ Briefly, all expired gas from the ventilator enters the 4- $\mathrm{L}$ mixing chamber, from which gas is sampled and analyzed to determine mixed expired oxygen $\left(\mathrm{FEO}_{2}\right)$ and carbon dioxide $\left(\mathrm{FECO}_{2}\right)$ concentrations. The expired gas leaving the mixing chamber is then mixed with room air so that the total flow $(\dot{Q})$ is constant. Diluted carbon dioxide fraction $\left(\mathrm{F}^{*} \mathrm{CO}_{2}\right)$ is measured, and the carbon dioxide production volume $\left(\mathrm{V}_{\mathrm{CO}_{2}}\right)$ is calculated as follows:

$$
\dot{\mathrm{V}} \mathrm{CO}_{2}=\dot{\mathrm{Q}} \times \mathrm{F}^{*} \mathrm{CO}_{2}
$$

The respiratory quotient (RQ), or the ratio of $\left(\dot{\mathrm{V}}_{\mathrm{CO}_{2}}\right.$ and $\dot{\mathrm{V}}_{2}$, is calculated by means of the Haldane transformation as follows:

$$
\mathrm{RQ}=\frac{1-\mathrm{FIO}_{2}}{\left(\mathrm{FIO}_{2}-\mathrm{FEO}_{2}\right) / \mathrm{FECO}_{2}-\mathrm{FIO}_{2}}
$$

where $\mathrm{FIO}_{2}$ indicates the inspired oxygen concentration sampled at the inspiratory limb of the ventilator circuit.

The $\dot{\mathrm{V}}_{2}$ is subsequently calculated from the RQ as follows:

$$
\dot{\mathrm{V}}_{2}=\dot{\mathrm{V}}_{\mathrm{CO}_{2}} / \mathrm{RQ}
$$

Gas volumes are corrected to standard conditions of dry gas, temperature and pressure. In this study, the artifact suppression mode was used. $\mathrm{FIO}_{2}$ was less than 0.4 in all subjects during the study. Changes in minute volume and $\mathrm{FIO}_{2}$ were avoided 15 minutes before measurement was taken. Calibration was performed before each experiment. The Deltatrac device measures $\dot{\mathrm{V}}_{2}$ every 1 minute, and the mean of at least 5 values was taken.

$\mathrm{Do}_{2}, \mathrm{CO}$, oxygen extraction ratio, and blood lactate. Arterial and mixed venous blood samples were taken from the peripheral arterial and pulmonary arterial catheters. Blood samples were analyzed for oxygen, carbon dioxide, lactate, and glucose levels with a blood analyzer (Radiometer ABL System 615; Radiometer Medical A/S, Brønshøj, Denmark). CO was then calculated with the direct Fick method according to the following equation: 


$$
\mathrm{CO}=\dot{\mathrm{V}}_{2} /\left(\mathrm{CaO}_{2}-\mathrm{C}_{\overline{\mathrm{v}}}\right)
$$

where $\mathrm{CaO}_{2}$ and $\mathrm{C} \overline{\mathrm{v}}_{2}$ are arterial and mixed venous oxygen contents, respectively. $\mathrm{Do}_{2}$ was then calculated by the following equation:

$$
\mathrm{Do}_{2}=\mathrm{CO} \times \mathrm{CaO}_{2}
$$

and oxygen extraction rate $\left(\mathrm{ERO}_{2}\right)$ was calculated by the following equation:

$$
\mathrm{ERo}_{2}=\mathrm{Vo}_{2} / \mathrm{Do}_{2}
$$

\section{Study Protocol}

Hemodynamic values, $\dot{\mathrm{V}}_{2}$, and rectal temperature were obtained, and blood samples were taken at the following times: after induction of anesthesia (baseline), 30 minutes after $\mathrm{CPB}$, and then every 30 minutes until 6 hours after CPB. Intravenous infusion of IGF-1 at $1.2 \mathrm{mg} / \mathrm{h}$ was commenced 1 hour after the termination of $\mathrm{CPB}$, when the subject was rewarmed and stabilized, and continued to 6 hours after the termination of CPB.

\section{Statistical Analysis}

Data are expressed as mean \pm SE. Comparisons of the values between baseline and after CPB within the group were carried out with the unpaired 2-tailed $t$ test. Comparisons of the changes of the values over the study period between the control and IGF-1 groups were performed with mixed linear regression for repeated serial measurements. The changes in each variable during the study period were analyzed with 1-way repeated measures of analysis of variance. Correlation between two data sets was assessed with the correlation coefficient.

\section{Results}

Figure 1 demonstrates $\dot{\mathrm{V}}_{2}, \mathrm{CO}, \mathrm{Do}_{2}, \mathrm{ERo}_{2}$, central temperature, and arterial blood lactate levels during the study period in the IGF-1 and control groups.

\section{Baseline Measures}

Piglets weighed $6.9 \pm 0.5 \mathrm{~kg}$ in the IGF-1 group $(\mathrm{n}=6)$ and $6.5 \pm 0.6 \mathrm{~kg}$ in the control group $(\mathrm{n}=6, P>.05)$. CPB times were $93 \pm 8$ minutes in the IGF-1 group and $80 \pm 4$ minutes in the control group $(P>.05)$. The baseline values of $\dot{\mathrm{V}}_{2}(7.55 \pm 0.60 \mathrm{vs} 7.77 \pm 0.55 \mathrm{~mL} /[\mathrm{min} \cdot \mathrm{kg}]), \mathrm{ERo}_{2}$ $(0.46 \pm 0.08$ vs $0.48 \pm 0.03)$, lactate $(1.88 \pm 0.68$ vs 2.20 $\pm 0.34 \mathrm{mmol} / \mathrm{L})$, and central temperature $\left(38.2^{\circ} \mathrm{C} \pm 0.4^{\circ} \mathrm{C}\right.$ vs $38.5^{\circ} \mathrm{C} \pm 0.4^{\circ} \mathrm{C}$ ) were lower in the IGF- 1 group than in the control group, whereas $\mathrm{CO}(0.29 \pm 0.05$ vs $0.23 \pm 0.02$ $\mathrm{L} /[\mathrm{min} \cdot \mathrm{kg}])$ and $\mathrm{Do}_{2}(19.74 \pm 3.93$ vs $16.36 \pm 1.43$ $\mathrm{mL} /[\mathrm{min} \cdot \mathrm{kg}])$ were higher; however, none of these differences were considered to be of statistical significance $(P>$ .05 for all).

\section{Changes After CPB}

The values of central temperature, $\dot{\mathrm{V}}_{2}, \mathrm{Do}_{2}, \mathrm{CO}$, and $\mathrm{ERO}_{2}$ at 30 minutes after $\mathrm{CPB}$ were lower than baseline for both the IGF-1 and control groups, except for $\mathrm{CO}$ in the IGF-1 group, which was slightly higher, but without statistical significance in all the values $(P>.05)$. Blood lactate levels were significantly higher than baseline values after CPB for both groups ( $P<.001$ for both). No correlations were found between the duration of $\mathrm{CPB}$ and $\dot{\mathrm{V}}_{2}$ immediately after CPB, at 1 hour after CPB, and at 6 hours after CPB. $(r=0.2$ to $0.4, P>.05$ for all).

\section{Comparison of Changes Between IGF-1 and Control Groups After CPB}

In the IGF-1 group, $\dot{\mathrm{V}}_{2}$ initially increased after CPB to 8.1 $\mathrm{mL} /(\mathrm{min} \cdot \mathrm{kg})$ at 2 hours (1 hour after the infusion of IGF-1). The increase was insignificant relative to the first measurements at 30 minutes after CPB $(P>.05)$. Between 2 and 6 hours, there was a significant fall in $\dot{\mathrm{V}}_{2}$ in the IGF-1 group $(P=.002) ; \dot{\mathrm{V}}_{2}$ in the control group also decreased during this period. The decrease in $\dot{\mathrm{V}}_{2}$ in the IGF-1 group was significantly greater than that in the control group $(P=.02)$. During the same period, central temperature remained relatively stable in the IGF-1 group, whereas it increased in the control group $(P=.008)$. Both $\mathrm{CO}$ and $\mathrm{Do}_{2}$ were higher in the IGF-1 group throughout the study period. During the last 4 hours, $\mathrm{CO}$ and $\mathrm{Do}_{2}$ showed increases in the IGF-1 group but remained at similar levels in the control group ( $P=.016$ and $P=.049$, respectively). As a result, $\mathrm{ERO}_{2}$ was significantly decreased in the IGF-1 group relative to the control group $(P=.012)$. Lactate decreased significantly in both groups $(P<.001)$, being significantly greater in the control group $(P=.015)$. Nonetheless, it had returned to the normal range $(<2.5 \mathrm{mmol} / \mathrm{L})$ by the end of the study period in both groups. The average doses of dobutamine and nitroglycerin and the fluid infusion were similar in both groups. In the IGF-1 group, an additional $20 \%$ glucose infusion was needed so that the blood glucose was maintained at levels similar to those in the control group $(>4 \mathrm{mmol} / \mathrm{L}, P>.05)$.

\section{Discussion}

This is the first study to assess the effects of IGF-1 on the balance between systemic $\dot{\mathrm{V}}_{2}$ and $\mathrm{Do}_{2}$ during the early hours after $\mathrm{CPB}$. Our data shows that intravenous infusion of IGF-1 significantly reduced $\mathrm{V}_{2}$ while maintaining the central body temperature and was associated with increased $\mathrm{CO}$ and $\mathrm{Do}_{2}$ during the first 6 hours after CPB. Therefore it improved the balance between $\dot{\mathrm{V}}_{2}$ and $\mathrm{Do}_{2}$, as indicated by a significant decrease in $\mathrm{ERO}_{2}$.

Effect of IGF-1 on $\dot{\mathrm{V}}_{2}$

It is well documented that $\dot{\mathrm{V}}_{2}$ increases during the early hours after $\mathrm{CPB},{ }^{15-19}$ and that the increase is related to central body temperature ${ }^{17,19}$ and to the systemic inflammatory response. ${ }^{18}$ The initial postoperative $\dot{\mathrm{V}}_{2}$ in our animals was lower than baseline in all the animals, as was central temperature, reflecting incomplete rewarming after 

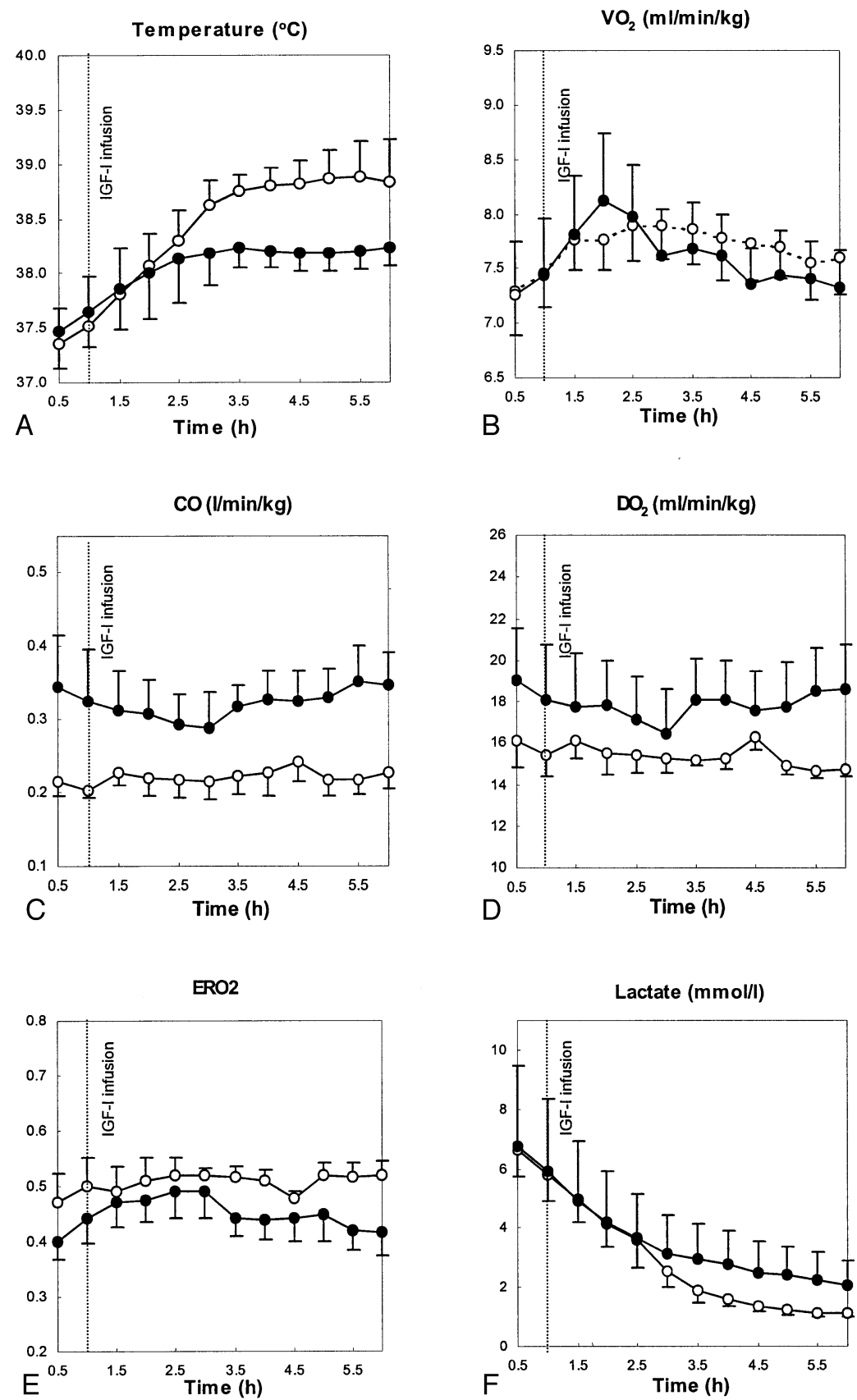

Figure 1. Values of central temperature $\left(A\right.$, in $\left.{ }^{\circ} \mathrm{C}\right), \dot{V}_{0_{2}}(B$, in $\mathrm{mL} /[\mathrm{min} \cdot \mathrm{kg}]), \mathrm{CO}(\mathrm{C}$, in $\mathrm{L} /[\mathrm{min} \cdot \mathrm{kg}]), \mathrm{Do}_{2}(\mathrm{D}$, in $\mathrm{mL} /[\mathrm{min}$ - $\mathrm{kg}]$ ), $\mathrm{ERO}_{2}(\mathrm{E})$, and arterial blood lactate $(\mathrm{F}$, in mmol/L) during first 6 hours after CPB in piglets receiving intravenous infusion of IGF-1 started (dashed line) 1 hour after CPB (filled circles, $n=6$ ) and in control group (open circles, $n=6$ ). Data points represent mean; error bars represent SE.

$\mathrm{CPB}$. The subsequent increase in $\dot{\mathrm{V}}_{2}$ during the following 2 or 3 hours in both groups is consistent with our own and other previous studies. ${ }^{15-19}$ However, there was a significant decrease in $\dot{\mathrm{V}}_{2}$ within 1 hour of starting the intravenous infusion of IGF-1.

Circulating IGF-1 levels are uniformly low in hypercatabolic states in various diseases, including after surgery with
CPB. ${ }^{1-5}$ This may be because the acquired growth hormone resistance fails to stimulate the synthesis and release of IGF-1, leading to the failure of the liver to produce IGF-1 in these circumstances. ${ }^{20,21}$ Administration of IGF-1 has been reported to attenuate protein catabolism and promote anabolism in postoperative ${ }^{6}$ and other critically ill subjects. ${ }^{7,9}$ Strock and colleagues ${ }^{7}$ reported that the decrease in IGF-1 
levels coincided with the period of most pronounced hypermetabolic response in a rat model of burn injury, and that treatment with IGF-1 reduced metabolic rate and $\dot{\mathrm{V}}_{2}$ and increased body weight significantly during a period of 14 days. Our study shows similar effects of IGF-1 in subjects after CPB. Interestingly, this response was accompanied by a significantly lower temperature $(P=.008)$ than in the control group, perhaps reflecting attenuated catabolism.

The mechanisms by which IGF-1 brings about this decrease in postoperative $\dot{\mathrm{V}}_{2}$ and metabolic rate in the postoperative animals cannot be explained by a direct effect on temperature control, because IGF-1 is not antipyretic. Rather, it is best explained by the substance's anabolic effects. While being stimulated by and mediating the growth stimulatory effect of growth hormone, IGF-1 exerts insulin-like metabolic effects with the cross-reaction with the insulin receptor on the energy substrates. It has been reported that administration of IGF-1 may increase protein synthesis ${ }^{6}$ as well as reduce protein breakdown, ${ }^{22}$ which may be associated with a reduction in $\dot{\mathrm{V}}_{2}$. In addition, the insulin-like effect of IGF-1 that promotes glucose as energy substrate by stimulating peripheral uptake and glucose oxidation instead of fat by suppressing lipolysis ${ }^{23}$ may further contribute to the reduction of $\dot{\mathrm{V}}_{2}$, because glucose oxidation is less oxygen demanding than is fat oxidation. ${ }^{22,24}$ Most studies assessing the anabolic effect of IGF-1 have been performed through a period of several days ${ }^{6,7}$; the significantly reduced $\dot{\mathrm{VO}}_{2}$ in our more acute study may indicate the anabolic effect of IGF-1 during the early hours after CPB. Although the mechanisms remain a matter of speculation, IGF-1 may provide beneficial effects in terms of both oxygen transport and anabolism to accelerate postoperative recovery after $\mathrm{CPB}$.

\section{Effect of IGF-1 on $\mathrm{Do}_{2}$}

$\mathrm{Do}_{2}$ is decreased after CPB primarily because of depressed cardiac function. ${ }^{25,26}$ The mechanism of the fall in cardiac function remains undefined but may be related to ischemiareperfusion injury, direct trauma, cytokines, and other myocardial depressants. ${ }^{27,28}$ Administration of IGF-1 has been reported to confer cytoprotection against ischemia and reperfusion injury and thus to accelerate recovery of postischemic cardiac function. ${ }^{25}$ In addition, IGF-1 may have distinct positive inotropic properties, leading to an increase in $\mathrm{CO} .{ }^{10,25}$ These factors may contribute to the significant increases in $\mathrm{CO}$ and $\mathrm{Do}_{2}$ in our study in the IGF-1 group relative to the control group. Unlike with inotropic drugs, however, the increase in cardiac contractility by IGF-1 may not come at the expense of increasing myocardial $\dot{\mathrm{V}}_{2}$, because it significantly increases myofilament free calcium sensitivity rather than increasing myocyte free calcium concentration. ${ }^{10}$ This unique property of IGF-1 may offer a significant therapeutic benefit in treating a myocardium with limited $\mathrm{Do}_{2}$, such as is often encountered in patients after surgery with CPB. Overall, intravenous infusion of IGF-1 improved the balance of oxygen transport, as indicated by a significant decrease in $\mathrm{ERO}_{2}$ relative to the control group. Assessment of blood lactate is increasingly used as a surrogate for tissue oxygen use, and although the decrease in blood lactate was significantly greater in the control group, it returned to the normal range in both groups.

\section{Effect of IGF-1 on Blood Glucose Levels}

The insulinlike effect of IGF-1 to stimulate glucose uptake and oxidation may be potentially beneficial in postoperative patients. Van den Berghe and associates ${ }^{29}$ recently reported that normalization of blood glucose levels with intensive insulin therapy reduced mortality and morbidity among critically ill patients in the surgical intensive care unit, regardless of whether they had a history of diabetes, although the mechanisms remain a matter of speculation. IGF-1 has been shown to be $6 \%$ as potent a hypoglycemic agent as insulin. ${ }^{30}$ Hypoglycemia remains a potential complication, although it has been reported that with continuous administration of IGF-1 the acute hypoglycemia may be less pronounced because of the transferring of free IGF-1 to its binding proteins. ${ }^{31}$ The blood glucose levels tended to decrease to low levels because of the relatively high dose of $1.2 \mathrm{mg} / \mathrm{h}$ in the piglets in our study. Thus careful attention to the prevention of hypoglycemia is essential when using IGF-1.

\section{Conclusion}

Intravenous infusion of IGF-1 improved oxygen transport by reducing $\mathrm{V}_{2}$ as well as increasing $\mathrm{CO}$ and $\mathrm{Do}_{2}$ during the first 6 hours after CPB in young piglets. This may have important clinical implications for the care of critically ill children after CPB surgery.

\section{References}

1. Cwyfan J, Hughes SC, Cotterill AM, Molloy AR, Cassell TB, Braude $\mathrm{N}$, et al. The induction of specific proteases for insulin-like growth factor-binding proteins following major heart surgery. J Endocrinol. 1992;135:135-45.

2. Gibson FA, Hinds CJ. Growth hormone and insulin-like growth factors in critical illness. Intensive Care Med. 1997;23:369-78.

3. Ross R, Miell J, Freeman E, Jones J, Matthews D, Preece M, et al. Critically ill patients have high basal growth hormone levels with attenuated oscillatory activity associated with low levels of insulin-like growth factor-I. Clin Endocrinol (Oxf). 1991;35:47-54.

4. Timmins AC, Cotterill AM, Hughes SC, Holly JM, Ross RJ, Blum W, et al. Critical illness is associated with low circulating concentrations of insulin-like growth factors-I and -II, alterations in insulin-like growth factor binding proteins, and induction of an insulin-like growth factor binding protein 3 protease. Crit Care Med. 1996;24:1460-6.

5. Yarwood GD, Ross RJ, Medbak S, Coakley J, Hinds CJ. Administration of human recombinant insulin-like growth factor-I in critically ill patients. Crit Care Med. 1997;25:1352-61.

6. Inaba T, Saito H, Fukushima R, Hashiguchi Y, Lin MT, Inoue T, et al. Effects of growth hormone and insulin-like growth factor 1 (IGF-1) treatments on the nitrogen metabolism and hepatic IGF-1-messenger 
RNA expression in postoperative parenterally fed rats. JPEN J Parenter Enteral Nutr. 1996;20:325-31.

7. Strock LL, Singh H, Abdullah A, Miller JA, Herndon DN. The effect of insulin-like growth factor I on postburn hypermetabolism. Surgery. 1990;108:161-4.

8. Tomas FM, Knowles SE, Owens PC, Chandler CS, Francis GL, Read LC, et al. Insulin-like growth factor-I (IGF-I) and especially IGF-I variants are anabolic in dexamethasone-treated rats. Biochem J. 1992; 282:91-7.

9. Unneberg K, Balteskard L, Mjaaland M, Sager G, Revhaug A. Growth hormone increases and IGF-I reduces the response to Escherichia coli infusion in injured pigs. Eur J Surg. 1997;163:779-88.

10. Cittadini A, Ishiguro Y, Stromer H, Spindler M, Moses AC, Clark R, et al. Insulin-like growth factor-1 but not growth hormone augments mammalian myocardial contractility by sensitizing the myofilament to $\mathrm{Ca}^{2+}$ through a wortmannin-sensitive pathway: studies in rat and ferret isolated muscles. Circ Res. 1998;83:50-9.

11. Merilainen PT. Metabolic monitor. Int J Clin Monit Comput. 1987;4: 167-77.

12. Weissman C, Sardar A, Kemper M. In vitro evaluation of a compact metabolic measurement instrument. JPEN J Parenter Enteral Nutr. 1990;14:216-21.

13. Joosten KF, Jacobs FI, van Klaarwater E, Baartmans MG, Hop WC, Merilainen PT, et al. Accuracy of an indirect calorimeter for mechanically ventilated infants and children: the influence of low rates of gas exchange and varying $\mathrm{FIO}_{2}$. Crit Care Med. 2000;28:3014-8.

14. Tissot S, Delafosse B, Bertrand O, Bouffard Y, Viale JP, Annat G. Clinical validation of the Deltatrac monitoring system in mechanically ventilated patients. Intensive Care Med. 1995;21:149-53.

15. Puhakka K, Rasanen J, Leijala M, Peltola K. Oxygen consumption following pediatric cardiac surgery. J Cardiothorac Vasc Anesth. 1994;8:642-8.

16. Licker M, Hohn L, Ralley FE. Relation between systemic oxygen uptake and tissue oxygen extraction following cardiac surgery. Eur $J$ Anaesthesiol. 1996;13:562-70.

17. Chiara O, Giomarelli PP, Biagioli B, Rosi R, Gattinoni L. Hypermetabolic response after hypothermic cardiopulmonary bypass. Crit Care Med. 1987;15:995-1000.

18. Oudemans-van Straaten HM, Jansen PG, te Velthuis H, Beenakkers IC, Stoutenbeek CP, van Deventer SJ, et al. Increased oxygen consumption after cardiac surgery is associated with the inflammatory response to endotoxemia. Intensive Care Med. 1996;22:294-300.

19. Li J, Schulze-Neick I, Lincoln C, Shore D, Scallan M, Bush A, et al. Oxygen consumption after cardiopulmonary bypass surgery in chil- dren: determinants and implications. J Thorac Cardiovasc Surg. 2000; 119:525-33

20. Wang P, Li N, Li JS, Li WQ. The role of endotoxin, TNF-alpha, and IL-6 in inducing the state of growth hormone insensitivity. World $J$ Gastroenterol. 2002;8:531-6.

21. Dahn MS, Lange MP, Jacobs LA. Insulinlike growth factor 1 production is inhibited in human sepsis. Arch Surg. 1988;123:1409-14.

22. Jacob R, Barrett E, Plewe G, Fagin KD, Sherwin RS. Acute effects of insulin-like growth factor I on glucose and amino acid metabolism in the awake fasted rat. Comparison with insulin. J Clin Invest. 1989;83: 1717-23.

23. Froesch ER, Zenobi PD, Zapf J. Metabolic effects of insulin-like growth factor I and possible therapeutic aspects in diabetes. In: Flyvbjerg A, Ørskov H, Alberti KG, editors. Growth hormone and insulinlike growth factor I in human and experimental diabetes. New York: John Wiley \& Sons; 1993. p. 109-29.

24. Giacca A, Gupta R, Efendic S, Hall K, Skottner A, Lickley L, et al. Differential effects of IGF-I and insulin on glucoregulation and fat metabolism in depancreatized dogs. Diabetes. 1990;39:340-7.

25. Otani H, Yamamura T, Nakao Y, Hattori R, Kawaguchi H, Osako M, et al. Insulin-like growth factor-I improves recovery of cardiac performance during reperfusion in isolated rat heart by a wortmanninsensitive mechanism. J Cardiovasc Pharmacol. 2000;35:275-81.

26. Wernovsky G, Wypij D, Jonas RA, Mayer JE, Hanley FL, Hickey PR, et al. Postoperative course and hemodynamic profile after the arterial switch operation in neonates and infants. A comparison of low-flow cardiopulmonary bypass and circulatory arrest. Circulation. 1995;92: 2226-35.

27. Braunwald E, Kloner RA. Myocardial reperfusion: a double-edged sword? J Clin Invest. 1985;76:1713-9.

28. Engler RL, Dahlgren MD, Morris DD, Peterson MA, Schmid-Schonbein GW. Role of leukocytes in response to acute myocardial ischemia and reflow in dogs. Am J Physiol. 1986;251(2 Pt 2):H314-23.

29. van den Berghe G, Wouters P, Weekers F, Verwaest C, Bruyninckx F, Schetz M, et al. Intensive insulin therapy in the critically ill patients. N Engl J Med. 2001;345:1359-67.

30. Guler HP, Zapf J, Froesch ER. Short-term metabolic effects of recombinant human insulin-like growth factor I in healthy adults. $N$ Engl J Med. 1987;317:137-40.

31. Flyvbjerg A, Ørskov H. Kidney tissue insulin-like growth factor I and initial renal growth in diabetic rats: relation to severity of diabetes. Acta Endocrinol (Copenh). 1990;122:374-8 